\title{
Tackling emerging infections: clinical and public health lessons from the West African Ebola virus disease outbreak, 2014-2015
}

\author{
Authors: Naomi F Walker ${ }^{A}$ and Christopher JM Whitty ${ }^{B}$
}

\begin{abstract}
The magnitude of the 2014-2015 West African Ebola virus disease outbreak was unforeseen at its onset and the initial international response was slow. The high mortality and the panic that this outbreak induced had a major effect on health systems. In this article we discuss some of the key public health and clinical lessons from this Ebola outbreak, including combining epidemiology, modelling and anthropology, and the initial evidence for the importance of fluid and antibiotic management.
\end{abstract}

KEYWORDS: Ebola virus disease, West Africa, outbreak, control, response

\section{Introduction}

The magnitude of the West African Ebola Virus Disease (EVD) outbreak (2014-2015) was unforeseen at its onset. The largest prior EVD outbreak, in Uganda, resulted in 425 cases. ${ }^{1,2}$ In less than 18 months, arising from a single index case, Sierra Leone, Liberia and Guinea recorded an estimated 11,147 direct deaths from EVD, including 507 deaths in healthcare workers, with many more deaths secondary to the breakdown and fear of healthcare services; for a time the epidemic threatened the region and potentially the continent. ${ }^{3,4}$ The high mortality and the panic this outbreak induced additionally had a major effect on health systems and economies, driving people further into poverty. It is important we learn the right lessons and avoid easy but wrong ones. In this article we discuss some of the key public health and clinical lessons from this Ebola outbreak (Box 1). For clinical practice the lessons come from this being a multisystem disease with high mortality ( $>70 \%$ untreated), which

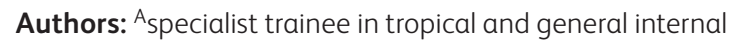
medicine, Clinical Research Department, London School of Hygiene and Tropical Medicine, London, UK; Bp professor of public and international health, Department of Infectious Diseases and Immunity, Imperial College London, London, UK, and Clinical Infectious Diseases Research Initiative, Institute of Infectious Disease and Molecular Medicine, University of Cape Town, Cape Town, South Africa
}

also has the potential to infect and kill many of those involved in treating cases. In public health terms this is a difficult to catch infection, with a relatively low force of transmission $\left(\mathrm{R}_{0}\right)$ only passed on by direct contact with body fluids; however the infection managed to paralyze three countries, and cause a regional and international risk of an epidemic within six months of the first case.

Factors contributing to the magnitude of the West African EVD outbreak: some public health lessons

It is widely accepted that the international community was too slow in responding to this outbreak, especially between March and June 2014 when the epidemic was relatively small and probably containable, but clearly gathering momentum. A combination of geographic, sociocultural, political, host and pathogen factors contributed to failure of the early response and the severity of the eventual epidemic. It would be wrong to place responsibility for the epidemic getting out of control on any single factor, including delayed response (Table 1).

\section{Box 1. Summary of key lessons for future emerging} infections.

\section{Public health lessons:}

Behavioural and political factors contribute to outbreak spread and should be central to the outbreak response.

> Assessment of the epidemiology of transmission, including $R_{0}$ and route of transmission, should inform the magnitude of the response to emerging infections.

\section{Clinical lessons:}

Screening for suspected cases requires a systematic approach and a high index of suspicion. Presentation may not be typical, but case identification is key to effective outbreak control. Reliable rapid tests would have helped early interventions.

$>$ Healthcare work-associated risks should be addressed to reduce healthcare worker morbidity and nosocomial transmission.

> Implementation of supportive management strategies may reduce mortality. Evaluation of such strategies is required to inform an evidence-based approach. 
Table 1. Population, pathogen and response factors in the West African EVD outbreak (2014-2015) that contributed to major outbreak potential.

\begin{tabular}{|c|c|c|c|}
\hline Factor & & West African EVD outbreak & Lessons for future outbreaks \\
\hline \multirow[t]{4}{*}{ Population } & Size & $\begin{array}{l}\text { Three countries affected rapidly. } \\
\text { > High transmission in large cities (Conakry, } \\
\text { Freetown and Monrovia) dramatically } \\
\text { increased case numbers. }\end{array}$ & $\begin{array}{l}\text { Complacency about infections typically affecting } \\
\text { marginalised or rural areas is misguided. } \\
\text { > Early interventions in an outbreak should target } \\
\text { densely populated areas. }\end{array}$ \\
\hline & Vulnerability & $\begin{array}{l}\text { Poor routine healthcare provision, water and } \\
\text { sanitation in affected areas. }\end{array}$ & $\begin{array}{l}\text { High-risk countries and communities should be } \\
\text { targeted for preventative measures, including } \\
\text { densely populated areas and informal settlements } \\
\text { with poor infrastructure, eg refugee camps. }\end{array}$ \\
\hline & & $\begin{array}{l}\text { Cultural factors including burial practices } \\
\text { increased risk. }\end{array}$ & $\begin{array}{l}\text { Improved understanding of sociocultural } \\
\text { determinants of infectious disease transmission } \\
\text { and implementation of interventions is required } \\
\text { for vulnerable populations. }\end{array}$ \\
\hline & & $\begin{array}{l}\text { Political agendas may have interfered with } \\
\text { case reporting and investigation. }\end{array}$ & $\begin{array}{l}\text { International agencies should oversee case } \\
\text { ascertainment. Areas of political instability and } \\
\text { conflict are likely to be at high risk. }\end{array}$ \\
\hline \multirow[t]{4}{*}{ Pathogen } & Infectivity & $\begin{array}{l}\text { Low infectious dose. Persistence of infectivity } \\
\text { postmortem. }\end{array}$ & \multirow{2}{*}{$\begin{array}{l}\text { Target carers and healthcare workers with } \\
\text { infection prevention and control education and } \\
\text { interventions. Equip hospitals and clinics with } \\
\text { permanent isolation facilities and provide regular } \\
\text { training. }\end{array}$} \\
\hline & Transmissibility & $\begin{array}{l}\text { Production of copious body fluids during } \\
\text { symptomatic stage increased transmissibility } \\
\text { and put healthcare workers at particular risk. }\end{array}$ & \\
\hline & Virulence & $\begin{array}{l}\text { > Severe disease in most cases. Likely few } \\
\text { asymptomatic cases. Mortality extremely high. }\end{array}$ & $\begin{array}{l}\text { Infections with respiratory and/or asymptomatic } \\
\text { transmission likely to be very difficult to control. }\end{array}$ \\
\hline & Unknowns & $\begin{array}{l}\text { Reservoir of Ebolavirus not well understood. } \\
\text { Immune response not well characterised. }\end{array}$ & $\begin{array}{l}\text { > Consider infections where reservoir, mechanism of } \\
\text { transmission and incubation period incompletely } \\
\text { understood to be particularly high risk. }\end{array}$ \\
\hline \multirow[t]{3}{*}{ Intervention } & Diagnostics & $\begin{array}{l}\text { Required complex, laboratory infrastructure, } \\
\text { no bedside test available. }\end{array}$ & $\begin{array}{l}\text { > Rapid diagnostics should be prioritized for EVD } \\
\text { and other pathogens with outbreak potential. }\end{array}$ \\
\hline & Vaccine & $>$ Not available & $\begin{array}{l}\text { Prioritise study of pathogens with high outbreak } \\
\text { potential and/or morbidity for funding and pre- } \\
\text { clinical study. }\end{array}$ \\
\hline & $\begin{array}{l}\text { Specific } \\
\text { treatments }\end{array}$ & $>$ Not available & $\begin{array}{l}\text { Knowledge sharing of interventions in the } \\
\text { pipeline. Establish gaps. Develop global forum to } \\
\text { form a consensus on research methods applicable } \\
\text { for future outbreaks. }\end{array}$ \\
\hline
\end{tabular}

$\mathrm{EVD}=$ Ebola virus disease

The initial delay was not however a failure of surveillance; reporting of clusters of suspicious cases to public health officials in Guinea occurred appropriately soon after the first Ebola death. Ebolavirus was identified as the cause of the epidemic in March 2014 and subsequently this was widely publicised by Médecins Sans Frontières among others. Calls to increase surveillance to 'prevent another Ebola epidemic' are therefore misleading. It was failure of analysis of the epidemiology once initial reports were made, and of the political response within the multilateral system that caused avoidable delay. ${ }^{5}$ Arguably, the simplest failure was to understand the implications of the force of transmission, $\mathrm{R}$ or $\mathrm{R}_{0}$. Where $\mathrm{R}_{0}$ is 1 in a non-immune population, on average 1 person gives it to 1 person and the disease is stable. If it is above 1 it will steadily increase; the initial $\mathrm{R}_{0}$ for this epidemic was probably between 1.5 and 2, where 2 would imply 1 person gives it to 2 people, who give it to 4 and so on. With a doubling time of roughly 30 days this meant that by Ebola doubling, then doubling again and so on, the number of cases would inevitably grow from very small numbers to very large ones in a surprisingly short time period. A 7-month delay with a doubling time of 30 days means an epidemic of 100 cases per week could become an epidemic of over 12,000 per week. In a peri-urban setting with little evidence of asymptomatic immunity, the potential for Ebola to spread was therefore considerable.

Many new infections, such as SARS, HIV, and here Ebola, are initially diseases of panic as much as they are of mortality, and this can hamper efforts to contain them. The Liberian 
government were accused of scaremongering to increase international aid when they raised the alarm about the extent of the outbreak in Liberia. ${ }^{6}$ Conversely, in Sierra Leone, authorities initially discouraged the reporting of suspected cases to avoid panic. ${ }^{6}$ This illustrates one of the key lessons of this epidemic; behavioural and political factors are at least as important to understanding and containing epidemics as the mathematics and biology. In this epidemic, a specific behavioural vulnerability existed due to traditional burial practices, where bodies are washed and touched during funeral ceremonies. In EVD, in contrast to many other epidemic diseases such as influenza, bodies remain highly infectious after death and therefore facilitate widespread transmission. For example, 85 Ebola cases were linked to one funeral in Guinea, with $18(21 \%)$ cases reporting direct contact with the body of a male midwife assistant at his funeral ceremony, who was later discovered to have died of Ebola. ${ }^{7}$ Anthropological insights were essential to understand how to address this: burying a body safely is relatively easy; burying a family member safely in a culturally acceptable way for one of the great rites of passage for any family is much harder.

Because Ebola is a disease which can only be caught from direct contact with symptomatic patients and their body fluids, identifying infectious individuals and isolating them is possible. This had been effective in previous outbreaks in Central and East Africa and was the mainstay of the public health response. The key to breaking the back of the epidemic was to get $\mathrm{R}_{0}$ below 1 , and to do that four broad strategies were used: minimise transmission in hospitals by rigorous use of infection control measures; encourage early isolation of symptomatic patients in the community; provide safe burials; and encourage social distancing to minimise risks of physical contact. ${ }^{8}$ All are easy to say and difficult to execute, but by heroic efforts by local and international medical and nursing staff and a considerable logistical exercise, including the use of troops from the affected countries, the UK and USA, this was eventually achieved and the epidemic was brought under control first in Liberia and then Sierra Leone. This demonstrated that relatively simple and old-fashioned methods targeting $\mathrm{R}_{0}$ can avert a major infectious threat. Many infections with epidemic potential would however require completely different approaches and it would be wrong to be lulled into a false sense of security that because it was possible with Ebola, similar isolation-based approaches would work for other diseases. Airborne infections, vector-transmitted infections, and infections with higher $\mathrm{R}_{0}$ (ie HIV) or asymptomatic transmission would not respond to the approach taken with Ebola. Much of the Ebola public health response to this outbreak had to be made up on the fly, and that will be true for other novel infectious threats which are bound to emerge.

\section{Clinical lessons from case management and isolation.}

Early in the course of the illness symptoms of Ebola may be non-specific and mistaken for other common infections such as influenza and malaria. ${ }^{9}$ In a large or widespread outbreak, Ebola cases may not present with typical symptoms such as fever, or have an identifiable risk factor for Ebola exposure, both components of suspected case definitions. ${ }^{10,11}$ Risk factors for exposure may not be accurately reported by patients or relatives at presentation. Epidemiological information on hotspot areas may lag behind patient presentation. As identification of cases is key to an effective outbreak response, the safest strategy is to have a high index of suspicion and set up systematic screening of all patients at the point of entry to a healthcare facility. The epidemic demonstrated the need for rapid diagnostic tests. A more rapid test would have significantly helped the early response; since PCR-based analysis was only possible safely in a few centers, diagnosis was inevitably delayed as samples were transported around the country.

Healthcare workers were both essential and extremely vulnerable in an outbreak of this severity. Healthcare workers detect and report early cases and provide ongoing surveillance throughout an outbreak. They are required to isolate and treat suspected and confirmed cases and those not directly involved in the response may inadvertently see cases in other settings. However, if healthcare worker safety is not paramount, high healthcare worker infection rates occur, propagating Ebola transmission in healthcare settings, increasing stigma associated with healthcare workers and healthcare facilities, and increasing the risk staff will not feel able to work. ${ }^{12}$ Data from Sierra Leone, May-October 2014, suggest that healthcare workers were at a 103fold increased risk of Ebola infection compared to the general population, demonstrating their vulnerability in this outbreak, with up to a $10 \%$ chance of infection per person-year. ${ }^{13}$

Healthcare worker infections and deaths from Ebola should be preventable by supply of and training in careful use of personal protective equipment (PPE). This was lacking in the early months of the outbreak despite the fact that similar measures are required for protection against Lassa fever, which is endemic in Sierra Leone. Once equipment and training were made available, ongoing support and re-training were required to ensure correct procedures were continually followed. Failure to decontaminate safely has contributed to healthcare worker infections. Some Ebola care facilities were able to employ extra staff specifically to supervise 'doffing' - removal of contaminated PPE - a routine but high-risk procedure. Supplies of PPE must be standardised and consistent so that staff who become accustomed to use of certain equipment are not forced to adjust their routine unexpectedly when a lapse in equipment supply occurs.

During the current outbreak, many healthcare workers lost their homes and were ostracised from their communities due to stigma. Some healthcare workers were forced to work in unsafe environments due to financial hardship and others were obligated to attend to sick friends and relatives in their community, increasingly as patients feared attending health facilities. Risk-allowance payments to staff directly involved in Ebola patient care were set up to mitigate this, but arrived too late. Fortunately, major infection prevention and control initiatives are now underway in the region, but social and economic factors that affect the healthcare workers and their communities must also be more rigorously addressed.

Current clinical management of Ebola is directed by expert opinion rather than clinical trial data. However, increasing observational data suggests that good supportive care consisting of optimal fluid rehydration, electrolyte replacement and broad-spectrum antibiotics to cover bacterial co-infection may significantly reduce mortality, which is likely to result from dehydration, electrolyte disturbance and neurological involvement largely. ${ }^{14-16}$ If these interventions were made available to patients earlier, the impact may be greater. This would rely on adequate isolation facilities and staff early in an outbreak, as previously discussed. Detailed case reports 
of repatriated health workers support the use of invasive ventilation for pulmonary oedema and renal replacement therapy for acute renal failure, although these will not be available in many resource-limited settings. ${ }^{17-20}$

Inferences on the efficacy of interventions from observational data are limited by selection bias and confounding from external factors, such as health-seeking behaviour and internal factors, such as human resources, which varied between Ebola care facilities and over time. Randomised controlled studies of specific interventions are still lacking despite efforts to improve this and it is a shame that the opportunity to systematically study simple interventions, such as intravenous hydration was missed. For much of the early outbreak in epidemic areas, staffing levels prohibited the kind of documentation necessary for controlled analysis of interventions. When human resources were finally mobilised, case numbers began to fall reducing the feasibility of interventional studies. It should have been possible to initiate clinical trials of fluids and antibiotics once the epidemic had peaked but while numbers were still high enough to allow statistically significant conclusions to be drawn. The availability of relatively simple technologies to improve information capture inside isolation units could be of great benefit in future, for example chlorine-resistant covers for electronic devices, such as cameras, mobile phones and tablets.

The need for research priorities to reflect predictable potential threats and not solely existing problems has been highlighted by this outbreak. While simple infection prevention and control strategies are sufficient to control an Ebola outbreak, they would not be sufficient to control an outbreak due to an infection with asymptomatic transmission or substantial respiratory spread. Considerable efforts to develop a vaccine for Ebola have not impacted on this outbreak as they came too late in this outbreak. If science and technology investments in neglected 'tropical' infections are made ahead of time, advances in rapid diagnostics, therapeutics or preventative measures could completely alter an outbreak trajectory, but this requires foresight by scientists, policymakers and research funders. ${ }^{21,22}$

\section{Conclusions}

In summary, failure of early control in the current Ebola outbreak was multifactorial, and policy and behavioural factors played a key role. Outbreak response strategies must be guided by the epidemiology and route of transmission. Clinicians on the front line require a systematic strategy for screening of patients to identify suspected cases, as typical presentation is not universal. Healthcare workers are extremely vulnerable and their welfare should be prioritised. Simple supportive management strategies, such as rehydration and antibiotic therapy, are likely to reduce mortality from Ebola and should be a priority in patient management. Studying the efficacy of these simple interventions should be a future priority.

\section{Conflicts of interest}

CJMW is chief scientific advisor to the UK Department for International Development.

\section{Acknowledgements}

NFW has been supported by the Wellcome Trust (094000) and the British Federation of Women Graduates (Ruth Bowden Scholarship).

\section{References}

1 Ebola virus disease in West Africa - the first 9 months of the epidemic and forward projections. N Engl J Med 2014;371:1481-95.

2 Okware SI, Omaswa FG, Zaramba S et al. An outbreak of Ebola in Uganda. Trop Med Int Health 2002;7:1068-75.

3 Mari Saez A, Weiss S, Nowak K et al. Investigating the zoonotic origin of the West African Ebola epidemic. EMBO Mol Med 2015;7:17-23.

4 World Health Organization. Ebola response roadmap situation report3 June 2015. Geneva: WHO, 2015. Available online at http://apps.who. int/ebola/en/current-situation/ebola-situation-report-3-june-2015 [Accessed 24 July 2015].

5 Philips M, Markham A. Ebola: a failure of international collective action. Lancet 2014;384:1181.

6 Médecins Sans Frontières. Pushed to the limit and beyond. A year into the largest ever Ebola outbreak. Geneva: MSF, 2015.

7 Victory KR, Coronado F, Ifono SO, Soropogui T, Dahl BA. Ebola transmission linked to a single traditional funeral ceremony Kissidougou, Guinea, December 2014-January 2015. MMWR Morb Mortal Wkly Rep 2015;64:386-8.

8 Whitty CJ, Farrar J, Ferguson N et al. Infectious disease: tough choices to reduce Ebola transmission. Nature 2014;515:192-4.

9 Fhogartaigh CN, Aarons E. Viral haemorrhagic fever. Clin Med 2015;15:61-6.

10 World Health Organization. Case definition recommendation for Ebola or Marburg virus diseases. Geneva: WHO, 2014.

11 Lado M, Walker NF, Baker P et al. Clinical features of patients isolated for suspected Ebola Virus Disease at Connaught Hospital, Freetown, Sierra Leone: a retrospective cohort study. Lancet Infect Dis 2015;15:1024-33.

12 Khan AS, Tshioko FK, Heymann DL et al. The reemergence of Ebola hemorrhagic fever, Democratic Republic of the Congo, 1995. J Infect Dis 1999;179 Suppl 1:S76-86.

13 Kilmarx PH, Clarke KR, Dietz PM et al. Ebola virus disease in health care workers - Sierra Leone, 2014. MMWR Morb Mortal Wkly Rep 2014;63:1168-71.

14 Chertow DS, Kleine C, Edwards JK et al. Ebola virus disease in West Africa - clinical manifestations and management. $N$ Engl J Med 2014;371:2054-7.

15 Bah EI, Lamah MC, Fletcher T et al. Clinical presentation of patients with Ebola virus disease in Conakry, Guinea. N Engl J Med 2015;372:40-7.

16 Schieffelin JS, Shaffer JG, Goba A et al. Clinical illness and outcomes in patients with Ebola in Sierra Leone. N Engl J Med 2014;371:2092-100.

17 Kraft CS, Hewlett AL, Koepsell S et al. The use of TKM-100802 and convalescent plasma in 2 patients With Ebola virus disease in the United States. Clin Infect Dis 2015,epub ahead of print.

18 Connor MJ Jr, Kraft C, Mehta AK et al. Successful delivery of RRT in Ebola virus disease. J Am Soc Nephrol 2015;26:31-7.

19 Kreuels B, Wichmann D, Emmerich P et al. A case of severe Ebola virus infection complicated by gram-negative septicemia. $N$ Engl J Med 2014;371:2394-401.

20 Lyon GM, Mehta AK, Varkey JB et al. Clinical care of two patients with Ebola virus disease in the United States. N Engl J Med 2014;371:2402-9.

21 Walker NF, Brown CS, Youkee D et al. Evaluation of a point-of-care blood test for identification of Ebola virus disease at Ebola holding units, Western Area, Sierra Leone, January to February 2015. Euro Surveill 2015;20:21073.

22 Jacob ST, Crozier I, Schieffelin JS, Colebunders R. Priorities for Ebola virus disease response in West Africa. Lancet 2014;384:1843.

Address for correspondence: Dr N Walker, 8th Floor, Commonwealth Building, Hammersmith Campus, Imperial College London, Du Cane Road, London W12 0NN, UK. Email: n.walker@imperial.ac.uk 